\title{
A TRANSFORMED COORDINATE MODEL TO PREDICT TIDE AND SURGE ALONG THE HEAD BAY OF BENGAL- APPLICATION TO CYCLONE OF 1991 AND 1970
}

\author{
Farzana Hussain \\ Department of Mathematics, Shahjalal University of Science \& Technology \\ Sylhet-3114, Bangladesh \\ Email: farzanahsn@gmail.com
}

Received 23.07.2014 Accepted 28.03.2015

\begin{abstract}
The head Bay of Bengal region is one of the most vulnerable regions for extreme water levels associated with severe tropical cyclones. The shallow nature of the head Bay, presence of a large number of deltas formed by major rivers and high tidal range are responsible for storm surge flooding in the region. Specifically, the rise and fall of tidal phases influence the height, duration, and arrival time of peak surge along the coast. The objective of the present study is to evaluate the tide-surge interaction during the super cyclone of 1991 and 1970. A transformed coordinate model is developed to estimate the possible water levels along the coast of Bangladesh.
\end{abstract}

Key Words: 1970 Bhola Cyclone, 1991 Cyclone, Tropical Storms, Surge, Shallow water equations, Transformation of Coordinates, Bay of Bengal

\section{Introduction}

There was extensive loss of life and property due to the deadliest super cyclone of April 29, 1991 which devastated large part of the Bangladesh coast, about 145,000 people died. The Cyclone of November 11, 1970 struck the Bangladesh coast and around 500,000 people lost their lives in that storm. Tropical storm along with surge is the most common destructive natural disaster that frequently hits the coastal region of Bangladesh. On average, five to six storm forms in this region every year. The associated surge is more dangerous rather than the storm itself. Sometimes it may rise from 9 to 15 meters [24] and rushes towards the land, which causes severe damage to the life and property. Because of its complex coastal geometry, Bangladesh suffers more than the surrounding countries. The Bay of Bengal is surrounded by the coasts from all sides except in the south where there is open sea. The coastal geometry is curvilinear in nature and the bending of the coastline is very high moreover, there are many small and big islands in the offshore region of the Bangladesh coast. Various factors significantly increase the surge levels along the coast of Bangladesh such as: shallowness of water, offshore islands, bending of coastlines, oceanic bathymetry, low lying islands, huge discharge through the rivers etc. Also, the head Bay of Bengal 
is a large tidal range area. Worst devastation may take place, if a storm approaches the coast at the time of high tide. Figure 1 shows the paths of the cyclones of April 1991 and November 1970.

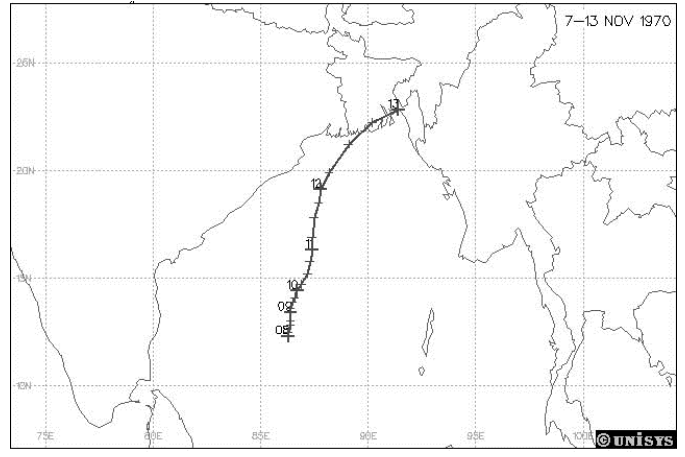

Fig. 1a: Path of the Cyclone of 1970. Source: Wikipedia website.

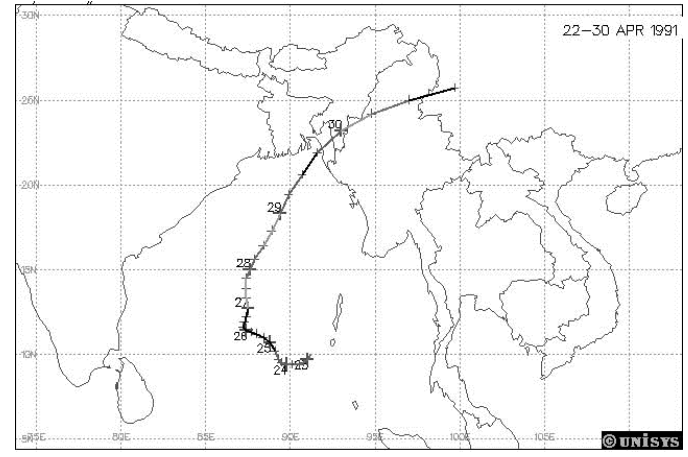

Fig. 1b: Path of the Cyclone of 1991. Source: Wikipedia website.

In order to minimize the loss of life and property, storm surge models have been developed for many parts of the world and have long been used to provide routine flood warnings along the coastal regions in several countries. Different numerical procedures and techniques are studied for the development of an accurate storm-surge prediction model for the Bay of Bengal region also. In a stair step model the curvilinear coastal and island boundaries are approximated along the nearest finite difference gridlines. So, if the grid size is not small, the representation of the coastal and island boundaries cannot be accurate. Again a very fine grid resolution near the coast and offshore region is necessary to incorporate the island boundaries and coastline properly through stair steps, which is not necessary away from the coast. Consideration of very fine resolution involves more computer memory and CPU time in the solution process and invites problem of numerical instability or complexity. Many cases were documented in [8] where the occurrence of abnormally high sea-surface levels in the Bay of Bengal led to coastal flooding and inundation. The effect of interaction between tide and surge in the Bay of Bengal was studied by [14, 17, 22, 27]. The study of [7] concluded that, the landfall time of cyclone and its interaction with the time of high tide determine the worst affected area of flooding during a cyclone. In the nested numerical model [24], a fine mesh numerical scheme was nested into a coarse mesh scheme for the Bay of Bengal. In the fine mesh scheme all the major islands were incorporated through proper stair step representation. Recently [19, 20,21] developed some models using nested numerical models. The complexity of the models lies in the matching of the boundary line of the fine mesh and coarse mesh scheme within the domain. The effect of presence of river on the surge development is discussed in [23] using boundary fitted stair step models. The expected total water levels for the coast of India, Pakistan and Myanmar are computed in [4, 10, 11, 12]. One of the limitations of those works is that the east-west boundaries of the analysis area and incorporated islands are considered as straight lines. 
In hydrodynamic models for coastal seas, bays, and estuaries the use of boundary-fitted curvilinear grids not only makes the model grids fit to the coastline, but also make the finite difference scheme simple and more accurate. In a boundary-fitted transformed coordinate model the curvilinear boundaries are transformed into straight ones, so that in the transformed domain regular finite difference technique can be used. [15] first used the partially boundary-fitted curvilinear grids in their transformed coordinate model for the east coast of India. The works [5, 15-18, 26] were also based on representing the coasts by curvilinear boundaries and transformation of coordinates. The limitations of these works is that the two opposite boundaries (the eastern and western) were considered as straight lines (open boundaries) and none of them incorporated any offshore islands. The main difficulty in incorporating the islands was that, the whereabouts of the island boundaries were undetectable in the transformed domain. A transformed coordinate model was developed in [25] where the major islands were incorporated.

The present study attempts to develop an accurate surge forecasting model based on transformation of coordinate. In the present study the complete boundary of the physical domain is represented by four boundary-fitted curves or functions. Based on them, all the four boundaries of islands are approximated by two generalized functions. Using mathematical transformations the physical domain becomes a square one and each island became a rectangle in the transformed domain. The vertically integrated shallow water equations are transformed into the new domain the regular explicit finite difference scheme with $100 \times 129$ grid points with time step 30 s is used to solve the shallow water equations. In this model the major islands Bhola, Hatiya, Sandwip are incorporated. The model is applied to compute the water levels due to tide and surge associated with the storm of 1991 and 1970 along the Bay of Bengal. For the analysis and verification of the model, results are taken at 8 locations along the coast. The locations are Hiron point, Barishal, Bhola (Island), Charjabbar, Hatiya (Island), Sandwip (Island) and Chittagong, Cox's Bazar. Unfortunately, a continuous record of tide-gage measurements throughout the duration of the cyclonic event is not available. However, we are unlikely to have access to any better data describing an actual surge event. Therefore, the best we can do is to make the most effective use of the limited data that are available for the Bangladesh coast for the storm of 1981 and 1985.

\section{Mathematical Formulation of the Problem}

\subsection{Boundary-Fitted Grids}

For the formulation of the model a system of rectangular Cartesian coordinates is used in which the origin, $O$, is the mean sea level (average level of sea surface). $O X, O Y, O Z$ are directed towards the south, the east and vertically upwards, respectively. The displaced position of the free surface is given by $\mathrm{z}=\zeta(x, y, t)$ and the position of sea floor is given by $z=-h(x, y)$, respectively. The northern coastal boundary of Bangladesh and the southern open boundary are given by $x=\beta_{1}(y)$ and $x=\beta_{2}(y)$, respectively. The western and eastern coastal boundaries are at $y=\delta_{1}(x)$ and $y=\delta_{2}$ $(x)$, respectively. This configuration is shown in Figure 2. 


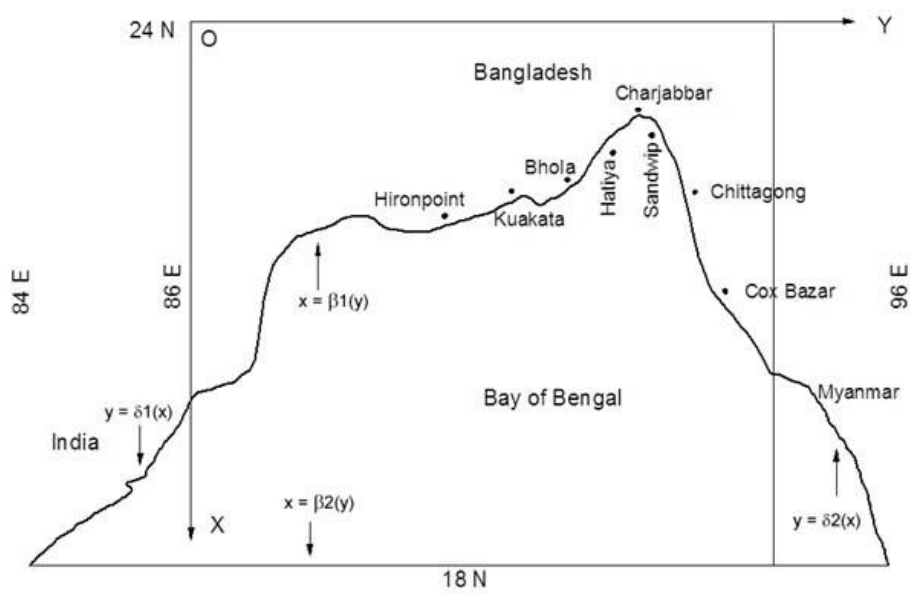

Fig. 2: Boundaries of the analysis area and the locations.

It may be seen in the Fig. 2 that the southern open boundary $x=\beta_{2}(y)$ is taken as a straight line but it can be considered as a curve also. Also it is to be noted that, the functions are not defined by explicit expressions, rather they are defined in tabular form. The boundary-fitted grids are generated through the following generalized functions:

The system of gridlines along $x=\beta_{1}(y)$ and $x=\beta_{2}(y)$ are given by the generalized function

$$
x=\left\{(m-q) \beta_{1}(y)+q \beta_{2}(y)\right\} / m,
$$

where $m$ and $q$ are constants and $0 \leq q \leq m$.

The system of gridlines along $y=\delta_{1}(x)$ and $y=\delta_{2}(x)$ are given by the generalized function

$$
y=\left\{(l-p) \delta_{1}(x)+p \delta_{2}(x)\right\} / l,
$$

where $l$ and $p$ are constants and $0 \leq p \leq l$.

Note that, Eq. (1) reduces to $x=\beta_{1}(y)$ and $x=\beta_{2}(y)$ for $q=0$ and $q=m$, respectively. Similarly, Eq. (2) reduces to $y=\delta_{1}(y)$ and $x=\delta_{2}(y)$ for $p=0$ and $p=l$, respectively. By proper choice of $q$, $m, p$, and $l$ we can generate the boundary-fitted curvilinear grid lines.

\subsection{Coordinate Transformation}

The coordinate transformations based upon a new set of independent variables $\xi$, $\eta$, and $t$ are given by

$$
\begin{aligned}
& \xi=\frac{x-\beta_{1}(y)}{\beta(y)}, \quad \beta(\mathrm{y})=\beta_{2}(y)-\beta_{1}(y), \\
& \eta=\frac{y-\delta_{1}(x)}{\delta(x)}, \quad \delta(x)=\delta_{2}(x)-\delta_{1}(x),
\end{aligned}
$$


These transforms the physical curvilinear domain into the following rectangular one

$$
0 \leq \xi \leq 1, \quad 0 \leq \eta \leq 1 .
$$

Also, the generalized functions given by Eqs. (1) and (2) transforms to

$$
\begin{aligned}
& \xi=q / m, \\
& \eta=p / l,
\end{aligned}
$$

The coastal boundary $x=\beta_{1}(y)$ or $\xi=0$ are obtained for $q=0$ and the open sea boundary $x=\beta_{2}$ (y) or $\xi=1$ are obtained for $q=m$. Similarly, for $p=0$, we have the western coastal boundary $y=$ $\delta_{1}(x)$ or $\eta=0$ and for $p=l$, we have the eastern coastal boundary $y=\delta_{2}(x)$ or $\eta=1$. The appropriate choice of the constants $m, l$ and the parameters $q, p$ in Eqs. (5) and (6) will generate the rectangular grid system in the transformed domain. Curvilinear boundaries of typical domain and the curvilinear grid system are shown in Fig. 3a. It may be noted that one of the boundaries is taken as straight line. In fact, it can be a curved line also. The corresponding boundaries and the rectangular grid system after the transformation are shown in Fig $3 \mathrm{~b}$.

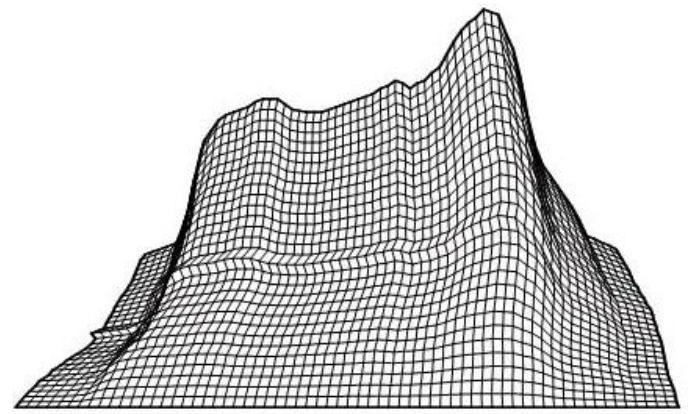

Fig. 3a: Curvilinear boundaries and the curvilinear grid system.

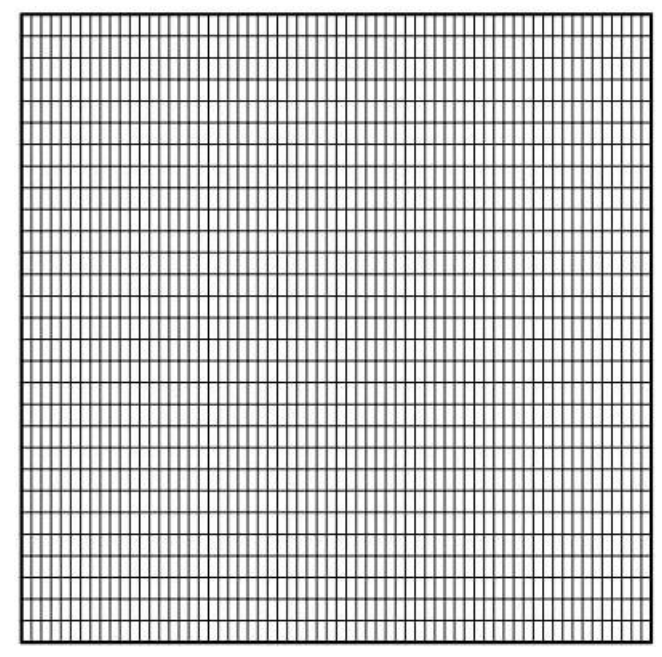

Fig. 3b: Boundaries and rectangular grid system in the transformed domain.

\subsection{Representation of Islands}

The northern and southern boundaries of an island are given by Eq. (1) and the western and eastern boundaries are given by Eq. (2). Using the transformations given in Eqs. (3) and (4) the four boundaries of the island are given by Eqs. (5) and (6). The northern and southern boundaries of an island can be expressed by Eq. (5) for two different values of $q$, say, $q_{1}$ and $q_{2}$ with $q_{1}<q_{2}$ Similarly, the western and eastern boundary of the island will be expressed by Eq. (6) for two different values of $p$, say, $p_{1}$ and $p_{2}$ with $p_{1}<p_{2}$. Thus the transformed boundaries of an island are expressed as 


$$
\xi=\frac{q_{1}}{m}, \quad \xi=\frac{q_{2}}{m}, \quad \eta=\frac{p_{1}}{l}, \quad \eta=\frac{p_{2}}{l},
$$

\subsection{Vertically Integrated Shallow Water Equations}

The vertically integrated shallow water equations given by [25] are

$$
\begin{aligned}
& \frac{\partial \zeta}{\partial t}+\frac{\partial}{\partial x}\{(\zeta+h) u\}+\frac{\partial}{\partial y}\{(\zeta+h) v\}=0 \\
& \frac{\partial u}{\partial t}+u \frac{\partial u}{\partial x}+v \frac{\partial u}{\partial y}-f v=-g \frac{\partial \zeta}{\partial x}+\frac{\tau_{x}}{\{\rho(\zeta+h)\}}-\frac{c_{f} u\left(u^{2}+v^{2}\right)^{1 / 2}}{(\zeta+h)}, \\
& \frac{\partial v}{\partial t}+u \frac{\partial v}{\partial x}+v \frac{\partial v}{\partial y}+f u=-g \frac{\partial \zeta}{\partial y}+\frac{\tau_{y}}{\{\rho(\zeta+h)\}}-\frac{c_{f} v\left(u^{2}+v^{2}\right)^{1 / 2}}{(\zeta+h)}
\end{aligned}
$$

The wind field over the physical domain is derived from the empirical formula given by [13]

$$
\begin{aligned}
V_{a} & =V_{o}(r / R)^{3 / 2} & \text { for } & r \leq R, \\
& =V_{o}(R / r)^{1 / 2} & \text { for } & r>R,
\end{aligned}
$$

Radial and tangential components of wind stress are derived by

$$
\left(\tau_{r}, \tau_{\theta}\right)=C_{D} \rho_{a}\left(u_{a}^{2}+v_{a}^{2}\right)^{1 / 2}\left(u_{a}, v_{a}\right),
$$

$\tau_{x}$ and $\tau_{y}$, the $x$ and $y$ component of wind stress in Eqs. (9) and (10) are derived from $\tau_{r}$ and $\tau_{\theta}$.

\subsection{The Boundary Conditions}

The boundary conditions used in this model are given by

$$
\begin{array}{ll}
u-v \frac{d}{d y}\left(\beta_{1}\right)=0, & \text { at } x=\beta_{1}(y), \\
u-v \frac{d}{d y}\left(\beta_{2}\right)=(g / h)^{1 / 2} \zeta, & \text { at } x=\beta_{2}(y), \\
v-u \frac{d}{d x}\left(\delta_{1}\right)=0, & \text { at } y=\delta_{1}(x), \\
v-u \frac{d}{d x}\left(\delta_{2}\right)=0, & \text { at } y=\delta_{2}(x),
\end{array}
$$

For generating tide in the basin the southern open sea boundary condition is taken as

$$
u-v \frac{d}{d y}\left(\beta_{2}\right)=(g / h)^{1 / 2} \zeta-2(g / h)^{1 / 2} a \operatorname{Sin}[(2 \pi t) / T+\varphi], \quad \text { at } x=\beta_{2}(y),
$$

where $a$ and $\varphi$ denotes the prescribed amplitude and phase of the tidal force, respectively and $T$ is the tidal period. 


\subsection{Governing Equations and Boundary Conditions in the Transformed Domain}

For the transformations given in Eqs. (3) and (4), we have

$$
\begin{aligned}
& \frac{\partial}{\partial x} \equiv \frac{\partial \xi}{\partial x} \frac{\partial}{\partial \xi}+\frac{\partial \eta}{\partial x} \frac{\partial}{\partial \eta} \\
& \frac{\partial}{\partial y} \equiv \frac{\partial \xi}{\partial y} \frac{\partial}{\partial \xi}+\frac{\partial \eta}{\partial y} \frac{\partial}{\partial \eta}
\end{aligned}
$$

Using these operators in Eqs. (8) - (10), we have the following transformed equations:

$$
\begin{aligned}
& \frac{\partial \zeta}{\partial t}+\frac{\partial}{\partial \xi}\{(\zeta+h) U\}+\frac{\partial}{\partial \eta}\{(\zeta+h) V\}=0 \\
& \frac{\partial u}{\partial t}+U \frac{\partial u}{\partial \xi}+V \frac{\partial u}{\partial \eta}-f v=-g\left[\frac{\partial \zeta}{\partial \xi} \frac{1}{\beta}-\frac{\partial \zeta}{\partial \eta} \frac{\left\{\left(\delta_{1}\right)_{x}+\eta \delta_{x}\right\}}{\delta}\right] \\
& +\frac{\tau_{x}}{\rho(\zeta+h)}-\frac{c_{f} u\left(u^{2}+v^{2}\right)^{1 / 2}}{\zeta+h}, \\
& \frac{\partial v}{\partial t}+U \frac{\partial v}{\partial \xi}+V \frac{\partial v}{\partial \eta}+f u=-g\left[\frac{\partial \zeta}{\partial \eta} \frac{1}{\delta}-\frac{\partial \zeta}{\partial \xi} \frac{\left(\left(\beta_{1}\right)_{y}+\xi \beta_{y}\right\}}{\beta}\right] \\
& +\frac{\tau_{y}}{\rho(\zeta+h)}-\frac{c_{f} v\left(u^{2}+v^{2}\right)^{1 / 2}}{\zeta+h},
\end{aligned}
$$

where

$$
\begin{aligned}
& U=u \frac{\partial \xi}{\partial x}+v \frac{\partial \xi}{\partial y}=\frac{u-\left\{\left(\beta_{1}\right)_{y}+\xi \beta_{y}\right\} v}{\beta}, \\
& V=u \frac{\partial \eta}{\partial x}+v \frac{\partial \eta}{\partial y}=\frac{v-\left\{\left(\delta_{1}\right)_{x}+\eta \delta_{x}\right\} u}{\delta},
\end{aligned}
$$

The boundary conditions in Eqs. (13) - (16) transforms to

$$
\begin{array}{ll}
U=0, & \text { at } \xi=0, \\
\beta U-(g / h)^{1 / 2} \zeta=0, & \text { at } \xi=1, \\
\beta U-(g / h)^{1 / 2} \zeta=-2(g / h)^{1 / 2} a \operatorname{Sin}[(2 \pi t) / T+\varphi], & \text { at } \xi=1, \\
V=0, & \text { at } \eta=0, \\
V=0, & \text { at } \eta=1,
\end{array}
$$

The normal component of velocity vanishes at each boundary of an island. Thus from Eq. (7), the boundary conditions for an island are given by

$$
\begin{array}{lllll}
U=0 & \text { at } & \xi=q_{1} / m & \& & \xi=q_{2} / m, \\
V=0 & \text { at } \quad \eta=p_{1} / l \quad \& \quad & \eta=p_{2} / l,
\end{array}
$$




\subsection{Numerical Setup of the Model}

The curvilinear grid system in the physical domain is generated by Eqs. (1) and (2). In the transformed domain the corresponding rectangular grid system is generated through Eqs. (5) and (6) with appropriate choices of $m, l, q$, and $p$. The curvilinear grid system is shown in Fig $3 \mathrm{a}$ and the corresponding rectangular grid system is shown in Fig $3 \mathrm{~b}$.

Let us define discrete coordinate points in the transformed domain by

$$
\begin{aligned}
\xi=\xi_{i}=(i-1) \Delta \xi, & i=1,2, \ldots, n_{i} \\
\eta=\eta_{j}=(j-1) \Delta \eta, & j=1,2, \ldots, n_{j}
\end{aligned}
$$

A sequence of time instant is given by

$$
t=t_{k}=k \Delta t, \quad k=1,2,3, \ldots
$$

In the computational domain we use the well known staggered grid system in which there are three distinct types of computational points. With $i$ even and $j$ even, the point is a $\zeta$-point at which $\zeta$ is computed. If $i$ is odd and $j$ is even, the point is a $u$-point at which $u$ is computed. If $i$ is even and $j$ is odd, the point is a $v$-point at which $v$ is computed. We choose $n_{i}(=100)$ to be even so that at the southern open boundary there are $\zeta$ - points and $v$-points only. Similarly, we choose $n_{j}(=129)$ to be odd thus ensuring that there are only $\zeta$-points and $v$-points at the eastern and western boundaries. The coastal boundary is approximated either along the nearest odd grid line ( $i=$ odd) given by Eq. (1) so that we have only $u$ - points on this part of the boundary or along the nearest odd grid line $(j=$ odd) given by Eq. (2) so that we have only $v$ - points along that part of the boundary. The island boundaries are also approximated in the same manner. Thus, the boundaries of the coast and of the islands are represented by such a system of stair steps that, at each segment (stair) there exists only that component of velocity which is normal to the segment. This is done in order to ensure the vanishing of the normal component of velocity at the boundaries in the numerical scheme.

The governing Eqs. (17) - (19) and the boundary conditions given by Eqs. (22) - (25) are discretized by finite difference (forward in time and central in space) and are solved by conditionally stable semi-implicit method using staggered grid. For numerical stability, the velocity components in Eqs. (18) and (19) are modeled in a semi-implicit manner. For example, in the last term of Eq. (18) the time discretization of $\tilde{u}\left(u^{2}+v^{2}\right)$ is done as $\tilde{u}^{k+1}\left(u^{2}+v^{2}\right)^{k}$ where the superscript $k$ and $k+1$ denote values at the present and advanced time levels, respectively. Moreover, the CFL criterion has been followed in order to ensure the stability of the numerical scheme. Along the closed boundary, the normal component of the velocity is considered as zero, and this is easily achieved through appropriate stair step representation as mentioned earlier.

The initial value of $\zeta, u$, and $v$ are taken as zero. The time step is taken as 30 s that ensures stability of the numerical scheme. In the solution process, a uniform value of 0.0026 for the friction coefficient $\left(C_{f}\right)$ and 0.0028 for the drag coefficient $\left(C_{D}\right)$ are considered throughout the physical domain. 
In this model the analysis area is extended from $84^{\circ} \mathrm{E}$ to $96^{\circ} \mathrm{E}$ along the coast of Bangladesh, India, and Mayanmar. The open sea boundary is situated along $18^{\circ} \mathrm{N}$ (Fig. 2). The east-west extent of the analysis area varies between $734 \mathrm{~km}$ and $1035 \mathrm{~km}$ and the north-south extent varies between 208 $\mathrm{km}$ and $541 \mathrm{~km}$. The analysis area has been divided to $100 \times 129$ grid points. Thus in the northsouth direction $\Delta x$ varies between $2.08 \mathrm{~km}$ and $5.41 \mathrm{~km}$ while in the east-west direction $\Delta y$ varies between $5.734 \mathrm{~km}$ and $8.085 \mathrm{~km}$. In the transformed domain we consider $\Delta \xi=1.0 /\left(n_{i}-1\right)$, and $\Delta \eta$ $=1.0 /\left(n_{j}-1\right)$ so that $q_{i}=(i-1) \Delta \xi=\xi_{i}$ and $p_{j}=(j-1) \Delta \eta=\eta_{j}$.

The offshore region of Bangladesh coast is full of big and small islands with a high density around the Meghna estuary. In this study it is possible to incorporate the small islands by considering very fine resolution in the numerical scheme; we consider the major islands Bhola, Hatiya, Sandwip more accurately (Fig. 2).

\section{Results and Discussions}

\subsection{Analysis of the Computed Surge Response}

The model is applied to compute the water levels due to tide and surge associated with two tropical storms that hit the coast of Bangladesh. To analyze the result we have chosen the storms of April 29, 1991(BOB01) and November 11, 1970 with maximum sustained anti-clock wise circulatory wind velocities of $260 \mathrm{~km} / \mathrm{h}$ and $225 \mathrm{~km} / \mathrm{h}$ respectively. Table. 1 gives the history of the above-mentioned storms, the data of which was received from the Bangladesh Meteorological Department (BMD) (Figure 1a and 1b). Both of these cyclonic storms that hit the coast of Bangladesh and were also favorable for high surge due to both wind intensity and path of their movement.

The hurricane of November 1970 intensified into a severe cyclonic storm on November 11 and began to turn towards the northeast as it approached the head of the Bay of Bengal. It reached its peak later that day with sustained winds of $185 \mathrm{~km} / \mathrm{h}(115 \mathrm{mph})$ and a central pressure of $966 \mathrm{hPa}$, equivalent to that of a Category 3 hurricane on the Saffir-Simpson Hurricane Scale. The cyclone made landfall on the Bangladesh coastline during the evening (around 0030 UTC) of November 12, around the same time as the local high tide. The Meteorological station in Chittagong, $95 \mathrm{~km}$ to the east of where the storm made landfall, recorded winds of $144 \mathrm{~km} / \mathrm{h}(89 \mathrm{mph})$ before its anemometer was blown off at about 2200 UTC. A ship anchored in the port in the same area recorded a peak gust of $222 \mathrm{~km} / \mathrm{h}(138 \mathrm{mph})$ about 45 minutes later. Figures $4 \mathrm{a}$ and $4 \mathrm{~b}$ depict the computed time series of surge levels associated with 1970 storm at different coastal locations. The water level at each location increases with time as the storm approaches towards the coast and finally there is recession. 
1. History of the chosen storms

\begin{tabular}{|c|c|c|c|c|c|c|c|}
\hline \multicolumn{4}{|c|}{ Storm of 1970} & \multicolumn{4}{|c|}{ Storm of 1991} \\
\hline Date & Hour & Lat. & Long. & Date & Hour & Lat. & Long. \\
\hline 0911 & 2200 & 14.10 & 86.00 & 2704 & 0000 & 11.80 & 87.50 \\
\hline 1011 & 0600 & 14.50 & 86.00 & 2704 & 0900 & 12.50 & 87.50 \\
\hline 1011 & 1800 & 16.00 & 86.00 & 2704 & 1200 & 13.00 & 87.50 \\
\hline 1111 & 1800 & 17.50 & 86.00 & 2704 & 1500 & 13.60 & 87.50 \\
\hline 1211 & 0600 & 19.00 & 87.50 & 2804 & 0000 & 14.50 & 87.50 \\
\hline 1211 & 1500 & 20.00 & 88.50 & 2804 & 1200 & 15.80 & 87.70 \\
\hline 1211 & 1800 & 21.50 & 90.00 & 2804 & 1400 & 16.50 & 88.00 \\
\hline 1311 & 0600 & 23.25 & 93.00 & 2904 & 0000 & 17.60 & 88.30 \\
\hline & & & & 2904 & 1200 & 19.80 & 88.40 \\
\hline & & & & 2904 & 1800 & 20.80 & 88.50 \\
\hline & & & & 3004 & 0000 & 22.00 & 91.00 \\
\hline & & & & 3004 & 0600 & 24.20 & 94.80 \\
\hline \multicolumn{4}{|c|}{ Storm of 1981} & \multicolumn{4}{|c|}{ Storm of 1985} \\
\hline Date & Hour & Lat. & Long. & Date & Hour & Lat. & Long. \\
\hline 0812 & 0100 & 13.30 & 85.25 & 2205 & 0000 & 14.00 & 88.50 \\
\hline 0812 & 0600 & 14.00 & 86.00 & 2205 & 0600 & 14.50 & 88.20 \\
\hline 0812 & 0900 & 14.50 & 86.20 & 2205 & 1800 & 15.50 & 87.50 \\
\hline 0912 & 0600 & 16.00 & 87.00 & 2305 & 0600 & 16.00 & 87.50 \\
\hline 0912 & 1800 & 17.50 & 87.00 & 2305 & 1200 & 17.00 & 87.50 \\
\hline 1012 & 0000 & 18.50 & 88.00 & 2305 & 1800 & 17.50 & 87.50 \\
\hline 1012 & 0900 & 19.50 & 88.50 & 2405 & 0900 & 18.00 & 88.00 \\
\hline 1012 & 1500 & 20.00 & 88.50 & 2405 & 1500 & 19.50 & 89.00 \\
\hline 1012 & 2100 & 21.00 & 89.00 & 2405 & 2100 & 20.50 & 90.50 \\
\hline 1112 & 0300 & 21.80 & 89.50 & 2505 & 0200 & 21.50 & 91.50 \\
\hline 1112 & 0900 & 22.75 & 90.00 & 2505 & 0800 & 23.50 & 92.50 \\
\hline
\end{tabular}

At Hiron Point a recession is started around $1700 \mathrm{hrs}$ of November 12, earlier than in any other location and about $7.5 \mathrm{hrs}$ before land fall of the storm (Fig. 4a). At Charjabbar a strong recession started around $2100 \mathrm{hrs}$ of November 12, about $3.5 \mathrm{hrs}$ before land fall of the storm. This recession takes place due to the backwash of water from the shore towards the sea. In fact, Hiron Point is situated far left (west) of the storm path and so the direction of the anti-clock wise circulatory wind becomes southerly (i. e. towards the sea) at Hiron Point long before the storm reaches the coast and thus driving the water towards the sea. The recession reaches up to $-2.0 \mathrm{~m}$ around 1800 hrs of 12 November. Charjabbar is situated immediate left (west) of the storm path and so the direction of the anti-clock wise circulatory wind becomes strongly southerly (i.e. towards the sea) at Charjabbar as the storm reaches the coast and thus driving the water towards the sea strongly. The recession reaches up to $-5.5 \mathrm{~m}$ around $0300 \mathrm{hrs}$ of 13 November. It may be noticed that the beginning of recession delays as we proceed towards east as is expected. We see that, the maximum elevation varies between $1.0 \mathrm{~m}$ (at Hatiya) to $4.9 \mathrm{~m}$ (at Char Jabbar). At Chittagong the computed water level increases up to $2.5 \mathrm{~m}$ before recession starts after 2200 of November 12 (Fig. 4b). As the storm made landfall at Chittagong, it caused a 10 metre (33 ft) high storm surge at the Ganges Delta. In the port at Chittagong, the storm tide peaked at about $4 \mathrm{~m}$

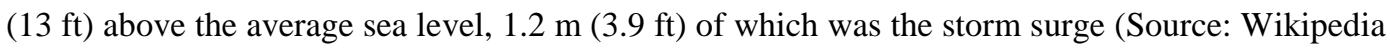
website). Thus, the computed results are in good agreements with the observed situation. 


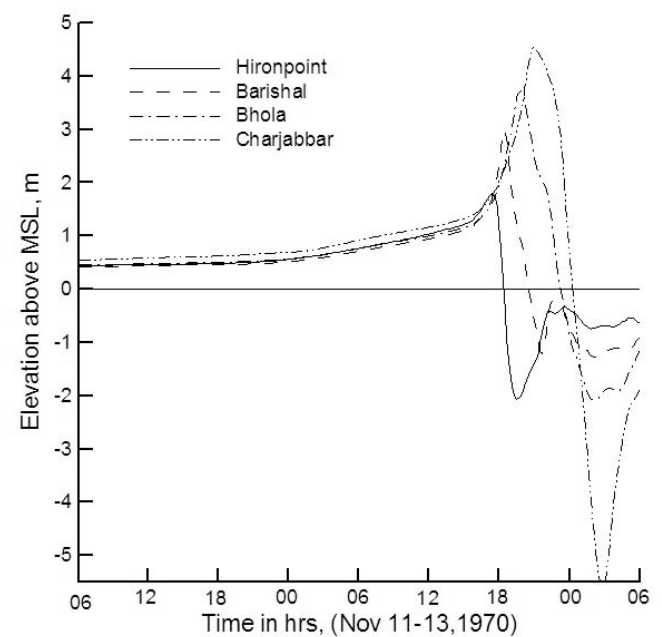

Fig. 4a: Computed time series of surge levels at the coastal locations associated with November 1970 storm

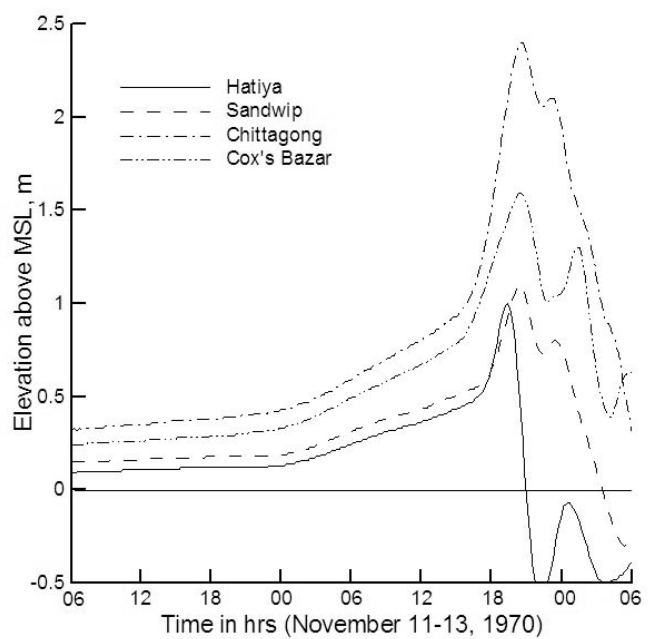

Fig. 4b: Computed time series of surge levels at the coastal locations associated with November 1970 storm

According to Bangladesh Meteorological Department (BMD) and Wikipedia website Super Cyclone BOB01 was formed on April 24. On the 28th and 29th, as the system increased its speed to the north-northeast, the cyclone rapidly intensified to a $260 \mathrm{~km} / \mathrm{h}$ or $160 \mathrm{mph}$ Cyclone, the equivalent to a Category 5 hurricane. The central pressure of the cyclone was $918 \mathrm{hPa}$. Late on the 29 th, it made landfall at a short distance south of Chittagong as a slightly weaker $250 \mathrm{~km} / \mathrm{h}$ or $155 \mathrm{mph}$ Category 4 Cyclone. The storm rapidly weakened over land, and dissipated on the $30^{\text {th }}$ April, 1991. Figure 5a, b depicts the computed surge levels associated with BOB01 at different coastal locations (without tidal consideration). It may be observed that, the maximum surge level is increasing with time as the storm approaches towards the coast and finally there is recession. At Hiron Point a recession is started around 1900 hrs of April 29, at Charjabbar a strong recession started around 0000 hrs of April 30. As before, Hiron Point is situated far left (west) of the storm path and so the direction of the anti-clock wise circulatory wind becomes southerly (i. e. towards the sea) at Hiron Point long before the storm reaches the coast and thus driving the water towards the sea. The recession reaches up to $-2.9 \mathrm{~m}$ around $2300 \mathrm{hrs}$ of 29th April. Charjabbar is situated immediate left (west) of the storm path and so the direction of the anti-clock wise circulatory wind becomes strongly southerly (i. e. towards the sea) at Charjabbar as the storm reaches the coast and thus driving the water towards the sea strongly. The recession reaches up to $-5.0 \mathrm{~m}$ around 0300 hrs of 30 April. It may be noticed that the beginning of recession delays as we proceed towards east as is expected. We see that, the maximum elevation varies between $1.0 \mathrm{~m}$ (at Hatiya) to $5.0 \mathrm{~m}$ (at Char Jabbar). At Chittagong the computed water level increases up to $2.6 \mathrm{~m}$ before recession starts after 0300 of April 30 (Fig. 5b). According to storm surge analysis by the Institute of Water Modeling (IWM) Bangladesh, the storm forced a 6 meter ( $20 \mathrm{ft}$ ) storm surge (including tide) inland over a wide area, killing at least 145,000 people and leaving as many as 10 million 
homeless. The computed surge heights are almost identical with the report of IWM. The similar information is obtained in the website of Wikipedia.

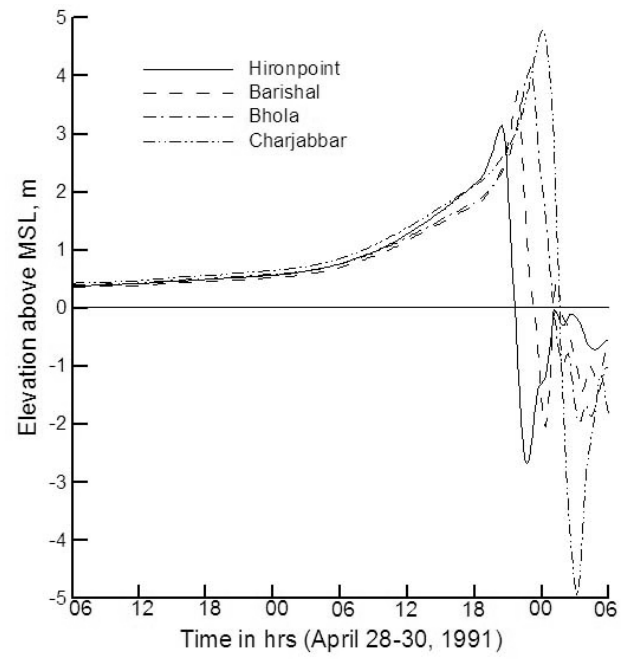

Fig. 5a. Computed time series of surge levels at the coastal locations associated with April 1991 storm.

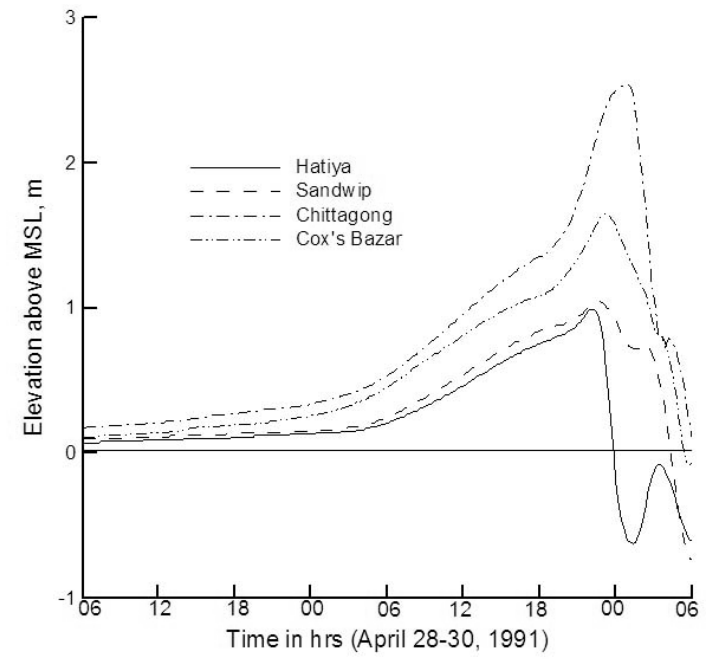

Fig. 5b. Computed time series of surge levels at the coastal locations associated with April 1991 storm.

Experiment is done to test the sensitivity of surge level with respect to the intensity of a storm. Figure 6 shows the peak surges along the coastal locations due to the storms of 1991 and 1970 respectively. The surge due to April 1991 storm is found to be much higher, which not only because of strong wind but also because of a favorable path for generating high surge [25].

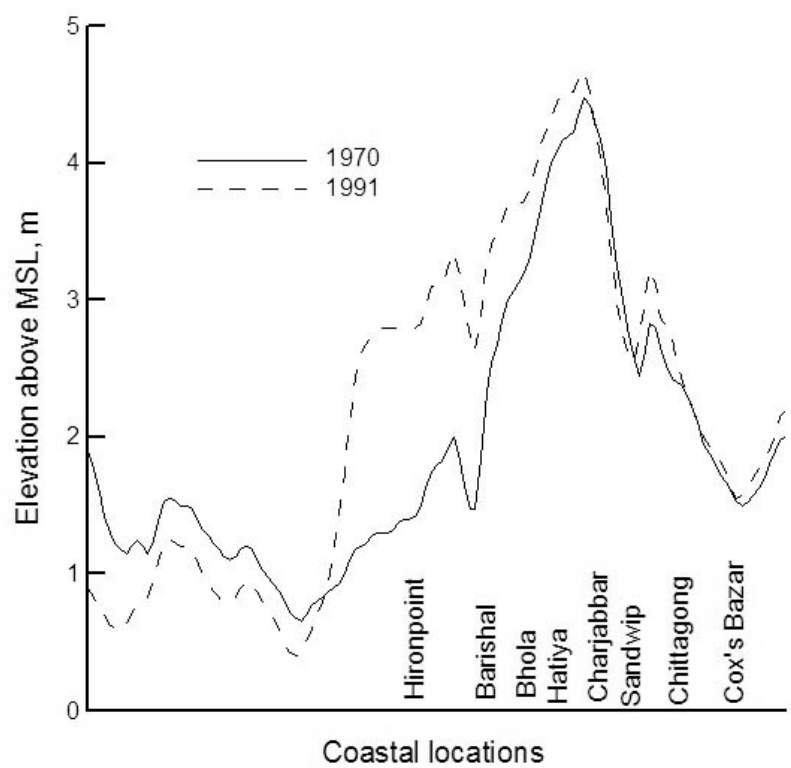

Fig. 6: Peak surges along the coastal locations due to the storms of 1970 and 1991. 


\section{Analysis of the Computed Tide and Tide-Surge Interaction}

We know, the astronomical tide is a continuous process in the sea, the surge due to tropical storms always interacts with the astronomical tide. So the pure tidal oscillation is the initial dynamical condition for interaction of tide and surge. A way of incorporating tidal oscillation with surge is to superimpose linearly the time series of surge response obtained through model simulation with that of oscillation obtain from tide table. The tidal information is generally available, as high and low values, four times a day in Bangladesh Tide Table.

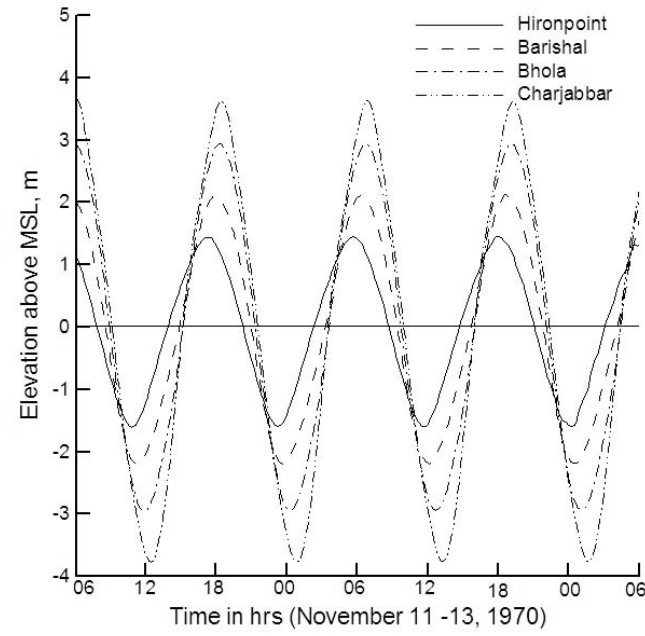

Fig. 7a: Computed tidal oscillations at different coastal locations at the time of the storm of 1970

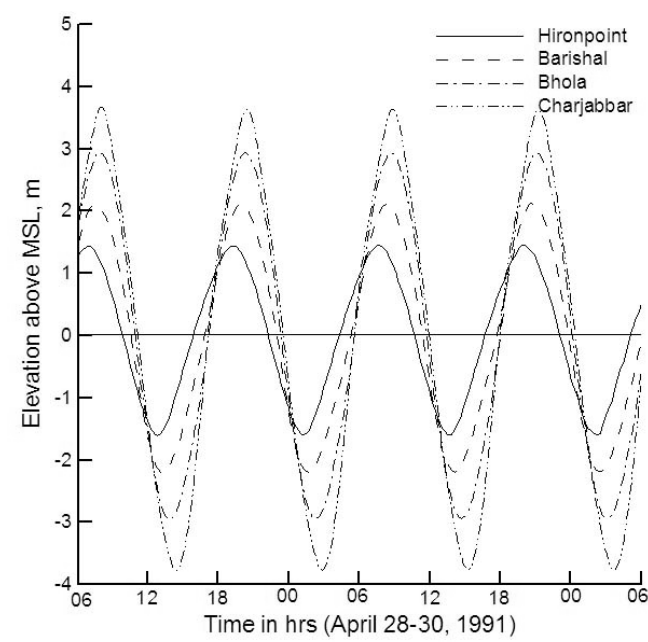

Fig. 7c: Computed tidal oscillations at different coastal locations at the time of the storm of 1991.

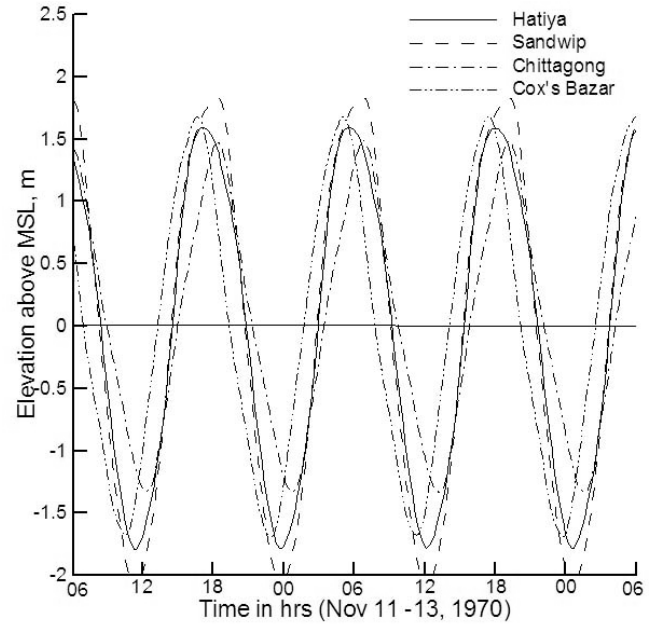

Fig. 7b: Computed tidal oscillations at different coastal locations at the time of the storm of 1970 .

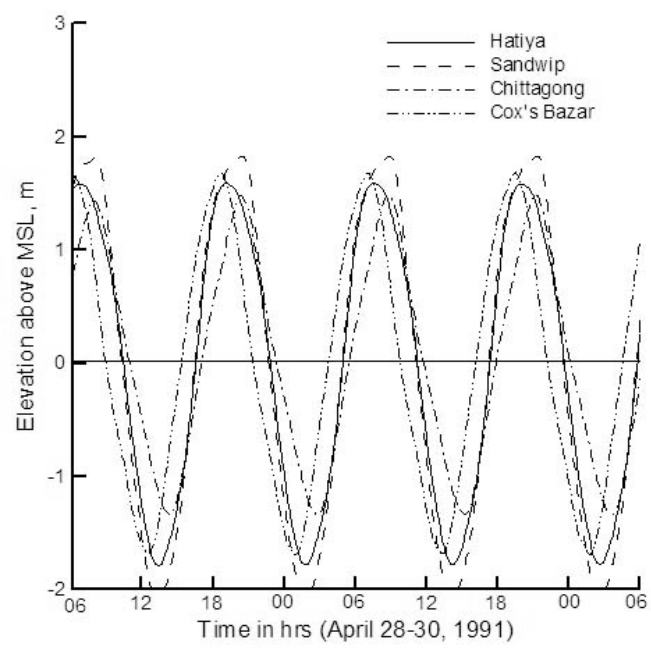

Fig. 7d: Computed tidal oscillations at different coastal locations at the time of the storm of 1991. 
The tide is generated in the model through the south open boundary condition (23b) with appropriate values of $a, T$, and $\varphi$ in absence of wind stress. It is observed that, though there is variation in the tidal period in the head Bay of Bengal, the average period is approximately of $M_{2}$ tide and so we choose $T=12.4 \mathrm{hrs}$. By trial it is found that $\varphi=0$ is a good choice for head Bay region. The information of the amplitude $a$ along the southern boundary is not available. We have chosen $a=0.6 \mathrm{~m}$ to test the response of the model along the coastal belt (Figure 7). It is found that response is exactly sinusoidal with the same period $(12.4 \mathrm{hrs})$, which is expected.

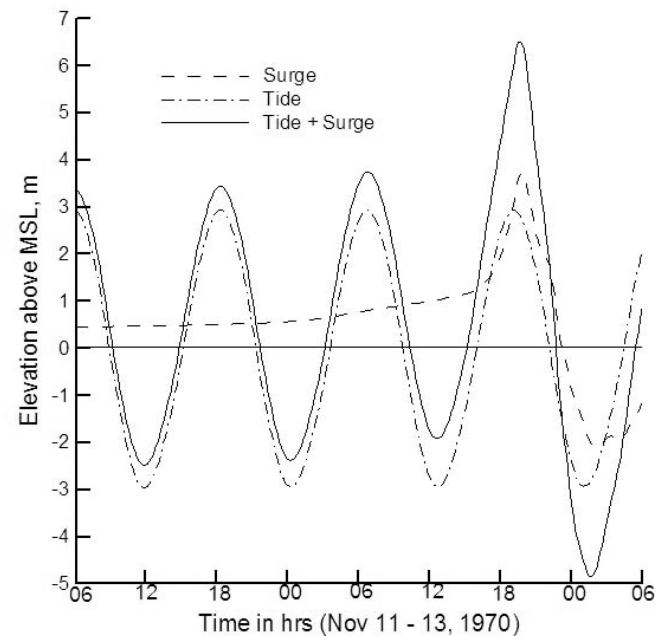

Fig. 8a: Computed tide, computed surge, and their linear interaction associated with November 1970 storm at Bhola.

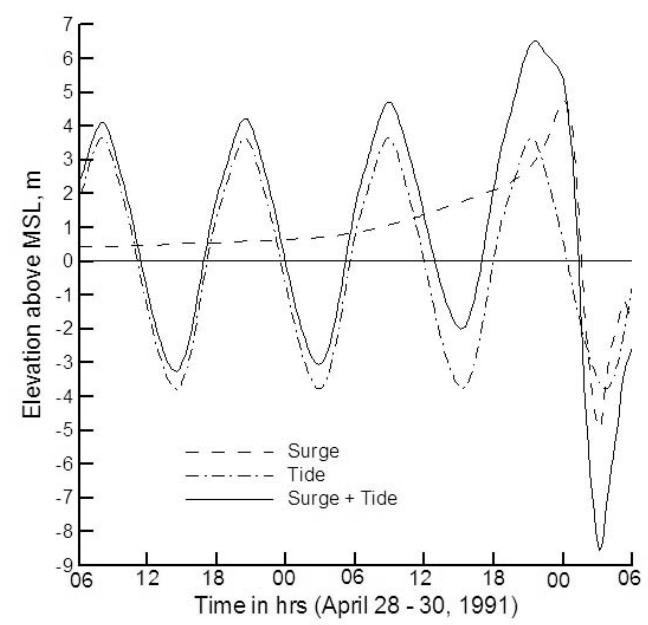

Fig. 8c: Computed tide, computed surge, and their linear interaction associated with November 1991 storm at Charjabbar.

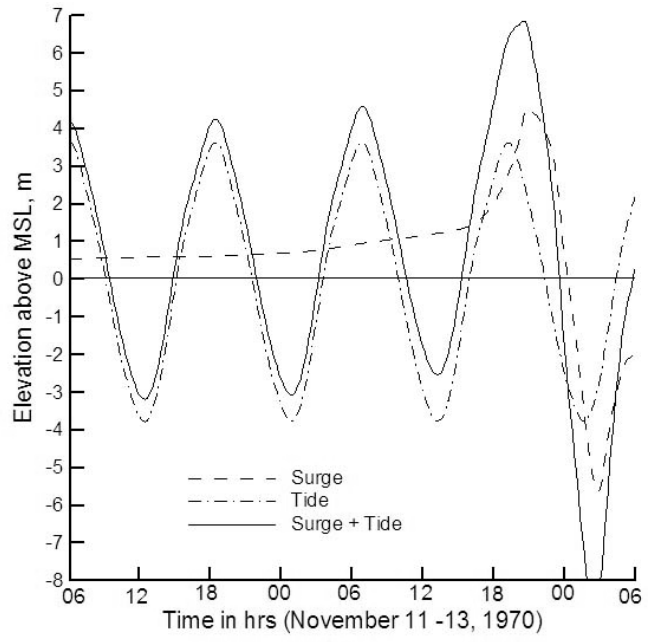

Fig. 8b: Computed tide, computed surge, and their linear interaction associated with November 1970 storm at Charjabbar.

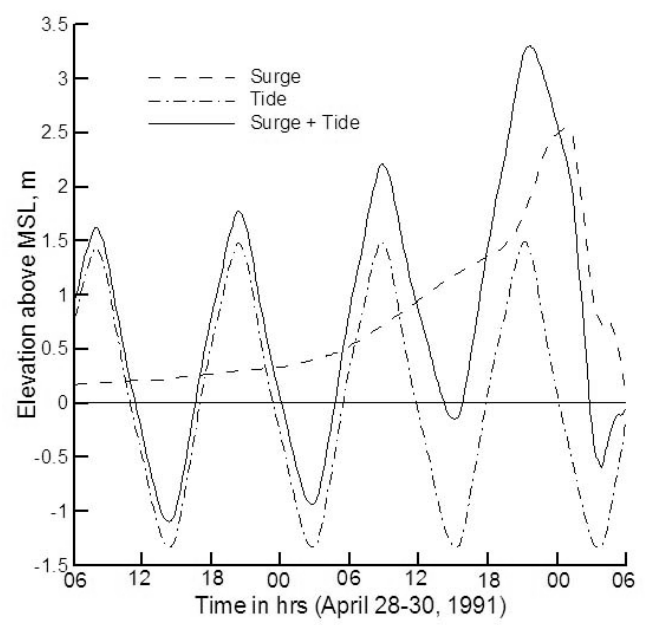

Fig. 8d: Computed tide, computed surge, and their linear interaction associated with November 1991 storm at Chittagong. 
About the phase it may be seen that Hatiya, Sandwip, Chittagong and Cox's Bazar are in the same phase of tidal oscillation. This is because of the fact that, they are very close to each other. Hence providing appropriate values of the amplitude $a$ along the southern open sea boundary condition the model may generate the actual tidal oscillation in the whole basin.

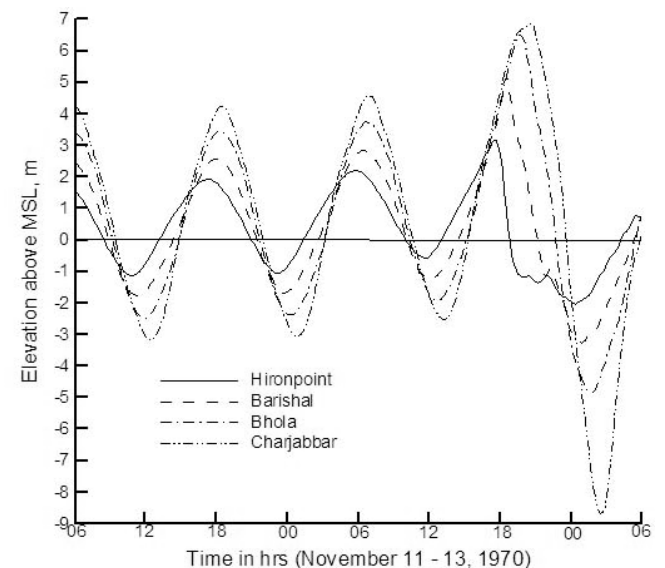

Fig. 9a: Total water levels (surge + tide) at different coastal locations due to 1970 storm.

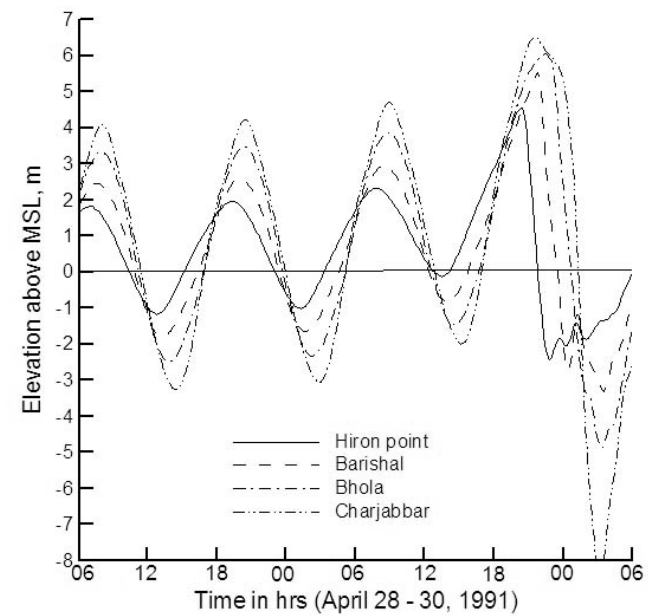

Fig. 9c: Total water levels (surge + tide) at different coastal locations due to 1991 storm.

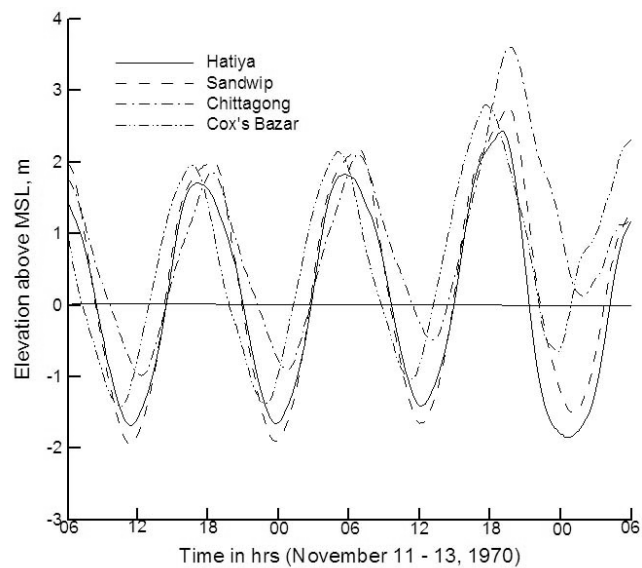

Fig. 9b. Total water levels (surge + tide) at different coastal locations due to 1970 storm.

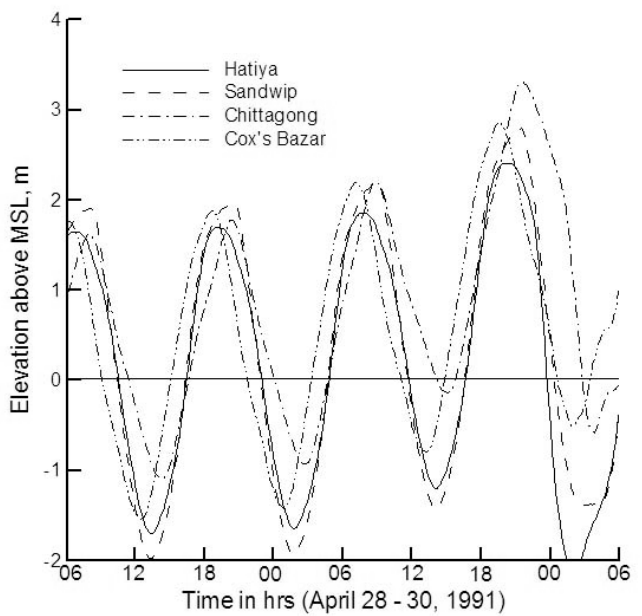

Fig. 9d: Total water levels (surge + tide) at different coastal locations due to 1991 storm.

Figure 8 shows the computed tide, computed surge, and their linear interaction associated with the considered storms at Bhola and Charjabbar for 1970, Charjabbar and Chittagong for 1991. Figure 9 shows the total water levels (Surge + tide) at different coastal locations. According to storm surge analysis by the Institute of Water Modeling (IWM), there was 4 to 6 meters surge along the coastal regions between Hiron point and Charjabbar of which about $2-3$ meter is due to the astronomical tide, because both the storms made landfall at the time of high tidal period. Thus, the 
computed water levels are almost identical with the report of IWM. The storm approaches the coast during high tide period and hence intensifies the water level due to interaction. At each location, because of weak wind the surge response is less when the storm is away from the coast and the total water level is dominated by tidal oscillation. On the other hand, because of very strong wind the water level is dominated by surge when the storm approaches the cost.

\subsection{Comparison Between Computed and Observed Time Series of Water Levels}

The verification of a model is dependent on the correct observational data. We could not compare our computed results to the observed data due to non availability of observed time series data for these two cyclones. The Hydrographic department of BIWTA collects water level data at different coastal locations through manual gauge readers. During a severe storm period it is not possible to stay in the gauge station to collect the data, so observed time series data are not available for these two storms. The results of the article are explained, compared and verified using the information obtained from the Institute of Water Modeling (IWM), Bangladesh Inland Water Transport Authority (BIWTA), Bangladesh Meteorological Department (BMD) and the website of Wikipedia and NASA.

However, some observed data were collected form BIWTA and used by Roy [12] for the storms of December 1981, May 1985 with maximum sustained anti-clock wise circulatory wind velocities of $36 \mathrm{~m} / \mathrm{s}$ and $42 \mathrm{~m} / \mathrm{s}$ respectively. The time histories of these storms are given in Table.1. We use two of them for our verification purpose. Figure 10 depicts the computed water levels (tide + surge), and observed water levels at Chittagong for 1981 storm and at Hatiya for $1985 \mathrm{storm}$. At Chittagong the computed water level is less than that of observation except in the final peak at $1200 \mathrm{hrs}$ of 11 December (Fig. 10a). At Hatiya the difference is observed in phase but with respect to amplitude the computed result is satisfactory (Fig. 10b). However, observed water levels are in good agreement with the computed results.

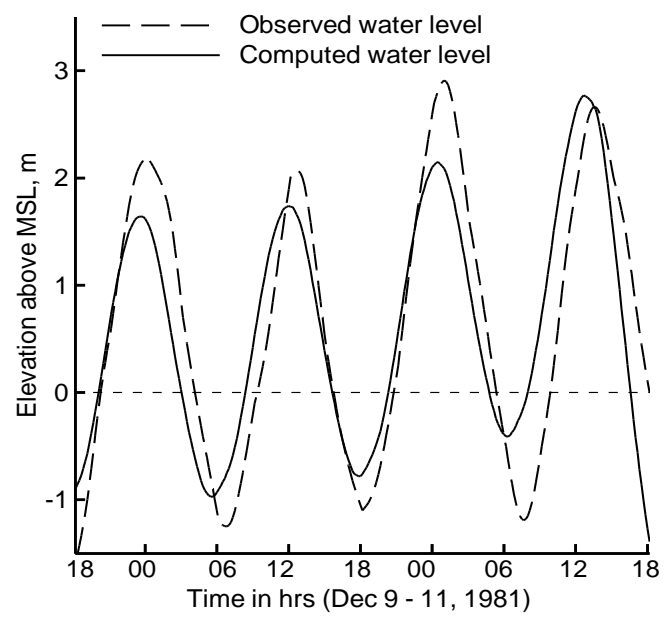

Fig. 10a: Observed and Computed water levels at Chittagong for the storm of 1981.

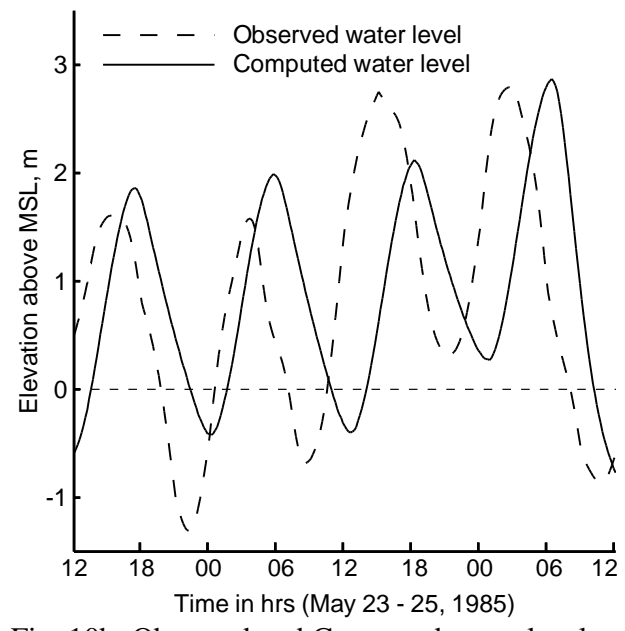

Fig. 10b: Observed and Computed water levels at Hatiya for the storm of 1985. 
Finally, Figure 11 shows the Contours (in meters) of equal sea surface elevation for peak surge along the Bay of Bengal. It is found that the region between Barishal (Kuakata) and Cox's Bazar is vulnerable for high surge, which is also in agreement with the observation.

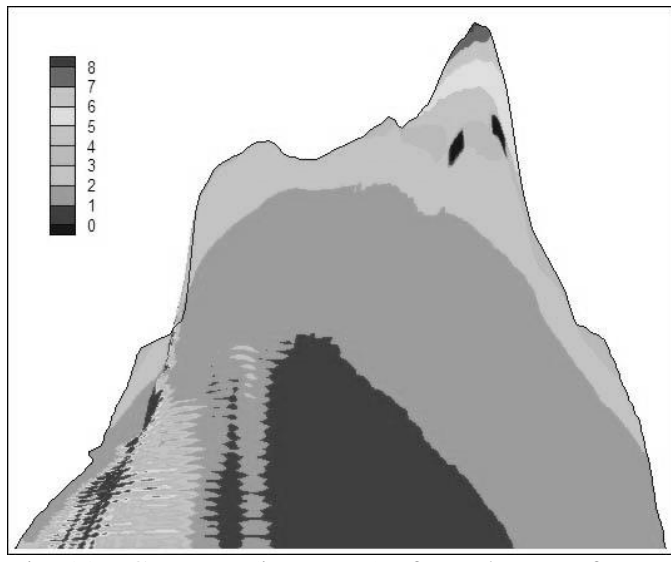

Fig. 11a: Contours (in meters) of equal sea surface elevation for peak water levels (surge + tide) along the Bay of Bengal for the storm of 1970.

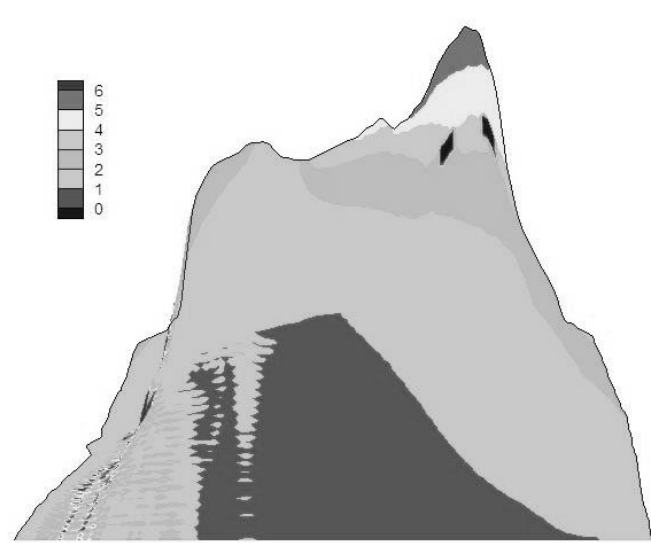

Fig. 11b: Contours (in meters) of equal sea surface elevation for peak water levels (surge + tide) along the Bay of Bengal for the storm of 1991 .

\section{Conclusion}

In this shallow water model all the four boundaries of the analysis area or island can be taken as curved boundary. Thus, it is applicable for any bay or estuary or even in any confined lake. This single model can be used to compute water levels along the East Coast of India and the coast of Myanmar. The model is also tested for $30 \times 65,60 \times 65,90 \times 91$ grid points with suitable time steps (results not shown) and the results are found to be in good agreement with the observation.

\section{REFERENCE}

[1] Bao, X.W., Yan, J., Sun, W. X, 2000, “A three-dimensional tidal model in boundary-fitted curvilinear grids", Estuarine, Coastal and Shelf Science Vol. 50, pp. 775-788.

[2] Das, P. K., 1972, "Prediction model for storm surges in the Bay of Bengal", Nature, Vol. 239, pp. 211-213.

[3] Das, P. K., Sinha M. C., Balasubrahmanyam, V, 1974, "Storm surges in the Bay of Bengal", Quart J. Roy. Met. Soc. 100, 437-449.

[4] Dube, S. K., Indu Jain, Rao, A. D., T. S. Murty, 2009, "Storm surge modelling for the Bay of Bengal and Arabian sea", Natural Hazards, Vol. 51, pp. 3-27.

[5] Dube S. K., Sinha, P. C., Roy, and G. D. , 1986, "The numerical simulation of storm surges in Bangladesh using a bay-river coupled model", Coastal Engineering, Vol. 10, pp. 85-101.

[6] Dube, S. K., Sinha, P. C., Roy, G. D., 1985, "The numerical simulation of storm surges along the Bangladesh coast”, Dyn. Atms. Oceans, Vol. 9, pp. 121-133.

[7] Flather RA (1994) A storm surge prediction model for the northern Bay of Bengal with application to the cyclonic disaster in April 1991. J Phys Oceanograph 24:172-190 
[8] Flierl, G. R., Robinson, A. R., 1972 "Deadly surges in the Bay of Bengal: Dynamics and storm tide tables", Nature, Vol. 239, pp. 213-215.

[9] Hussain Farzana, 2013, "A Transformed Coordinates Shallow water Model for the Head of the Bay of Bengal using Boundary-Fitted Curvilinear Grids", East Asian Journal on Applied Mathematics, Vol 3, No 1, pp.27-47.

[10] Indu Jain, Neetu Agnihotri, Chittibabu, P., Rao, A. D., Dube, S. K., Sinha P. C., 2006, "Simulation of storm surges along Myanmar coast Using a location specific Numerical model”, Natural Hazards, Vol. 39, pp. 71-82.

[11] Indu Jain, Rao, A. D., Dube, S. K., V. Jitendra, 2010, "Computation of Expected total water levels along the east coast of India", Journal of coastal research, Vol. 26, No 4, pp. 681-687.

[12] Indu Jain, Chittibabu, P., Neetu Agnihotri, Dube, S. K., Rao, A. D., Sinha P. C., 2007, "Numerical Storm surge model for India and Pakistan", Natural Hazards, Vol. 42, pp. 67-73.

[13] Jelesnianski, C. P., 1965, "A numerical calculation of storm tides induced by a tropical storm impinging on a continental shelf", Mon. Wea. Rev. Vol. 93, pp. 343-358.

[14] Johns B., Ali, A., 1980, "The numerical modeling of storm surges in the Bay of Bengal", Quart. J. Roy. Met. Soc. Vol. 106, pp. 1-18.

[15] Johnson, B. H., 1982, "Numerical modeling of estuarine hydrodynamics on a boundary fitted coordinate system", Numerical Grid Generation (Thompson, J., ed.) Elsevier, pp. 419 - 436.

[16] Johns B., Dube, S. K., Mohanti, U. C., Sinha, P. C., 1982, The simulation of continuously deforming lateral boundary in problems involving the shallow water equations; Computers and Fluids, Vol. 10, pp. 105-116.

[17] Johns, B., Rao, A. D., Dube, S. K., Sinha P. C., 1985, "Numerical modeling of tide-surges interaction in the Bay of Bengal", Phil. Trans. R. Soc. of London A313, pp. 507-535.

[18] Johns B. Dube, S. K. Mohanti, U. C., Sinha, P. C. , 1981, "Numerical simulation of surge generated by the 1977 Andhra cyclone", Quart. J. Roy. Soc. London, Vol. 107, pp. 919-934.

[19] M. M. Rahman, A. Hoque, G. C. Paul and M. J. Alam, 2011, "Nested Numerical Schemes to Incorporate Bending Coastline and Islands of Bangladesh and Prediction of Water Levels due to Surge", Asian Journal of Mathematics and Statics, Vol. 4, No. 1, pp. 21 -32.

[20] M. M. Rahman, A. Hoque, G. C. Paul, 2011, "A Shallow Water Model Water Model for the coast of Bangladesh and Applied to Estimate water levels for AILA", Journal of Applied Sciences, Vol. 11, No. 24, pp. 3821 -3829.

[21] M. Mizanur Rahman, G. Chandra Paul and A. Hoque, 2011, "A Cyclone Induced Storm Surge forecasting Model for the coast of Bangladesh with Application to the Cyclone Sidr", International Journal of Mathematical Modelling and Computations, Vol. 1 No. 2, pp. 77-86.

[22] Murty TS, Flather RA, Henry RF (1986) The storm surge problem in the Bay of Bengal. Prog Oceanogr, 16:195-233

[23] Neetu Agnihotri, Chittibabu, P., Indu Jain, Rao, A. D., Dube, S. K., Sinha P. C. , 2006, “A Bay-River Coupled Model for storm surge prediction along the Andhra coast of India", Natural Hazards, Vol. 39, pp. 83-101.

[24] Roy, G. D. , 1995, "Estimation of expected maximum possible water level along the Meghna estuary using a tide and surge interaction model", Environment International, Vol. 21, No. 5, pp. 671-677. 
[25] Roy G. D., 1999, "Inclusion of offshore islands in transformed coordinates shallow water model along the coast of Bangladesh", Environment international, Vol. 25, No. 1, pp. 67-74.

[26] Sinha, P. C., S. K. Dube, and G. D. Roy, 1986, "Numerical simulation of storm surges in Bangladesh using a multi-level model", Int. J. for Num. methods in fluids, Vol 6, pp. 305311.

[27] Sinha PC, Rao YR, Dube SK, Rao AD, Chatterjee AK (1996) Numerical investigation of tide-surge interaction in Hooghly estuary, India. Marine Geod 19:235-255.

[28] Sheng, Y. P., 1989, “On modelling three- dimensional estuarine and marine hydrodynamics", Three- dimensional Models of Marine and Estuarine Dynamics (Nihoul J. C.J, ed.) Elsevier Oceanography Series, Vol. 45, pp. 35-54.

[29] Spaulding, M. L., 1984, “A vertical averaged circulation model using boundary-fitted coordinates”, Journal of Physical Oceanography, Vol. 14, pp. 973 - 982.

[30] Thompson, J.F., Frank, C., Thames, F.C., Mastin, C.W., 1974, "Automatic numerical generation of body-fitted curvilinear systems for tied containing any number of arbitrary twodimensional bodies", Journal of Computational Physics, Vol. 15, pp. 229-319.

[31] Wikipedia web site - http://en.wikipedia.org/wiki/1970_Bhola_cyclone

[32] Wikipedia web site -http://en.wikipedia.org/wiki/1991_Bangladesh_cyclone

[33] http://en.wikipedia.org/wiki/List_of_Bangladesh_tropical_cyclones 